\title{
UV Absorbance of Aqueous DNA
}

\section{Pivovarenko Yuri Vadimovich}

Research and Training Center 'Physical and Chemical Materials Science' under Kyiv Taras Shevchenko University and NAS of Ukraine, Kiev, Ukraine

\section{Email address: \\ y.pivovarenko@gmail.com}

\section{To cite this article:}

Pivovarenko Yuri Vadimovich. UV Absorbance of Aqueous DNA. European Journal of Biophysics. Vol. 3, No. 3, 2015, pp. 19-22. doi: $10.11648 /$ j.ejb.20150303.11

\begin{abstract}
The UV absorption spectra of water with different electric charge (potential) were obtained. It was shown that UV absorption spectra of water with negative electric charge (potential) have the sharp peaks with maximum in the range $190-200 \mathrm{~nm}$ and UV absorption spectra of water with positive electric charge (potential) have the wide peaks with maximum in the range $200-220 \mathrm{~nm}$. It was asked to explain this absorption. It was also established that UV absorption spectra of water solutions of surface inactive substances have sharp peaks with a maximum in the range $190-200 \mathrm{~nm}$ and UV absorption spectra of solutions of surface active substances have the wide peaks with a maximum in the range $200-$ $220 \mathrm{~nm}$. The UV absorption spectra of DNA solutions, which were prepared on the water with different electric charge (potential), were obtained. It was shown that these spectra are dependent on the electric charge (potential) of water used. It was proposed that UV absorption spectra of aqueous DNA reflect mostly the spectral properties of charged water or charged cuvette.
\end{abstract}

Keywords: UV Absorption Spectra, Electric Charge, Electric Potential, DNA

\section{Introduction}

UV absorption spectra of aqueous DNA have two characteristic peaks: 1 - with maximum in the range $190-$ $220 \mathrm{~nm}$, and 2 - with maximum at $260 \mathrm{~nm}$; the existence of such peaks is due to the $n \rightarrow \pi$ - and $\pi \rightarrow \pi$-transitions of electrons bases, in [1]. Thus, based on existed theory, the shape of the UV absorption spectra of aqueous DNA should to be universal and characteristic. But by analyzing our early results, we concluded that it is not so. For that reason we supposed that peaks on UV absorption spectra of aqueous DNA have other nature.

Giving this supposition, we have taken into account that during the experiments spectral light interacts not only with dissolved DNA, but also with water and the quartz cuvette. Need to say that their contribution in the total UV absorption of aqueous DNA, no one, as we know, does not include.

\section{Main Body}

For experimental verification of our assumptions, we studied separately the UV absorption of water used, the components of buffers and spectrophotometer cuvette.

\section{Materials and Methods}

Sodium salt of DNA was purchased from Fluka (Switzerland); other reactive were purchased from Ukrreachim (Ukraine).

To UV spectra recording Specord UV VIS (Carl Zeiss Jena, Germany) was used.

\section{Results and Discussion}

\subsection{UV Absorbance of Electrifies Water Solutions}

Since contact with air and glassware, water can electrify, in $[2,3]$, we investigated the UV absorption of electrified water. It was found that UV absorption spectra distilled water, filtered through the activated carbon, have the sharp peaks with maximum at $195 \mathrm{~nm}$ (fig 1, spectrum 2) and UV absorption spectra distilled water, filtered through the silica gel, have the broad peaks with maximum in the range $200-$ $220 \mathrm{~nm}$ (fig 1, spectrum 3).

It was also found that UV absorption spectra of water solutions from the cathode department of electrolyzer, i.e. with negative potential, have the peaks with maximum in the range $190-200 \mathrm{~nm}$ and water solutions from the anode 
department of electrolyzer, i.e. - with positive potential, peaks with maximum in the range $200-220 \mathrm{~nm}$.

Therefore we supposed that water with negative electric charge (potential) most of all absorbs the light with wavelengths in the range $190-200 \mathrm{~nm}$, and water with positive electric charge (potential) - the light with wavelengths in the range $200-220 \mathrm{~nm}$. Giving this supposition, we took into account that the silica gel absorbs the aqueous anions and activated carbon - the aqueous cations, in [2]; thus, when the water filtration trough silica gel to acquire a positive charge, and trough activated carbon - negative.

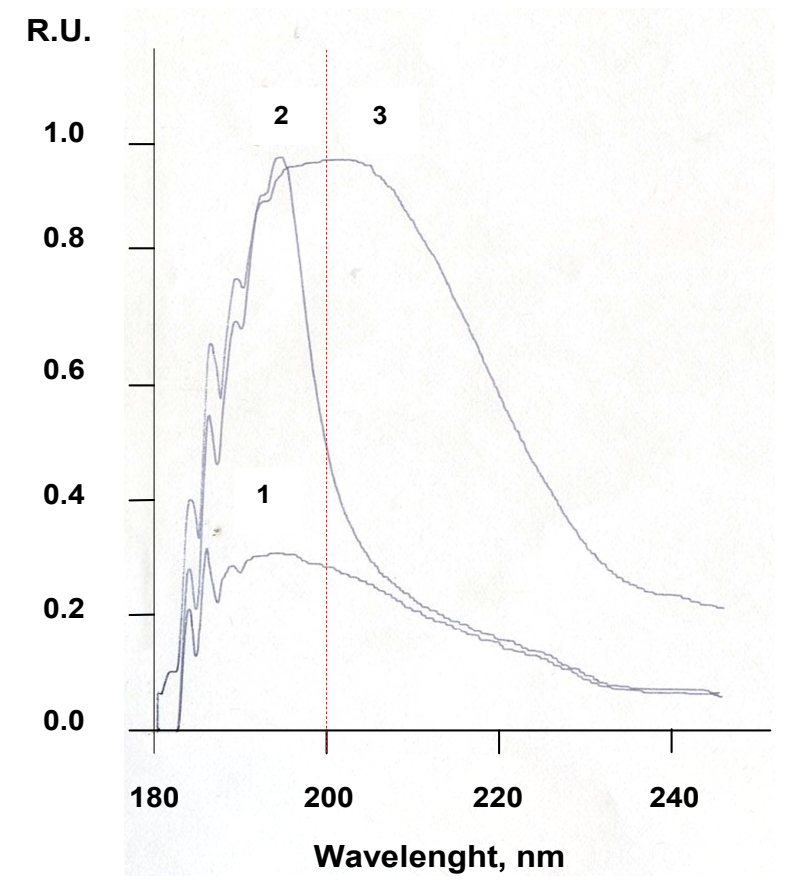

Fig. 1. UV absorbance spectra of the water: 1 - fresh distilled water; 1 water, filtered through activated carbon; 2 - water, filtered through silica gel. The spectra were not processed.

\subsection{UV Absorbance of Aqueous DNA}

UV absorption spectra of DNA solutions prepared with waters, filtered through activated carbon and silica gel, were obtained (fig. 2). It was found that these water solutions affect both on the absorbance in range $190-220 \mathrm{~nm}$ and on the absorbance at $\sim 260 \mathrm{~nm}$.

(It should be noted that the similar dependence was observed by us also for some albumin and melanin, in [4].)

Building on the existing theory, in [1], can suppose that in the water, filtered through activated carbon (i.e., with negative charge), DNA exists in the most structured state (fig. 2 , spectrum 1), and in the water, filtered through silica gel (i.e., with positive charge), - in the most melted state (fig. 2, spectrum 2).

Thus, an electric charge (potential) of water used affects not only on DNA. For example, it defines the form of salt crystals (fig. 3-5). By analyzing these results, it should be remembered that the DNA used has a salt nature.

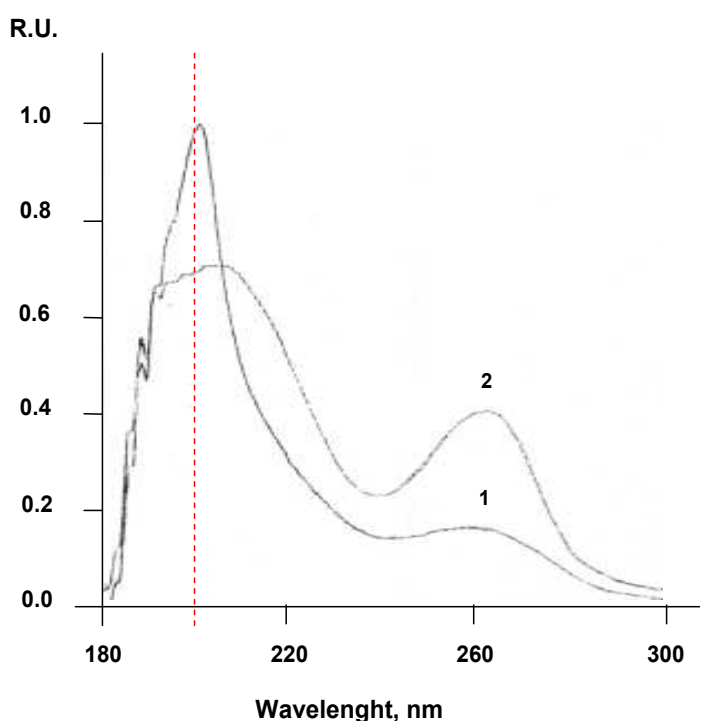

Fig. 2. UV absorbance spectra of the aqueous DNA ( 20 $\mu \mathrm{g} / \mathrm{ml}): 1-D N A$, dissolved in water filtered through activated carbon; $2-D N A$, dissolved in water filtered through silica gel. The spectra were not processed.

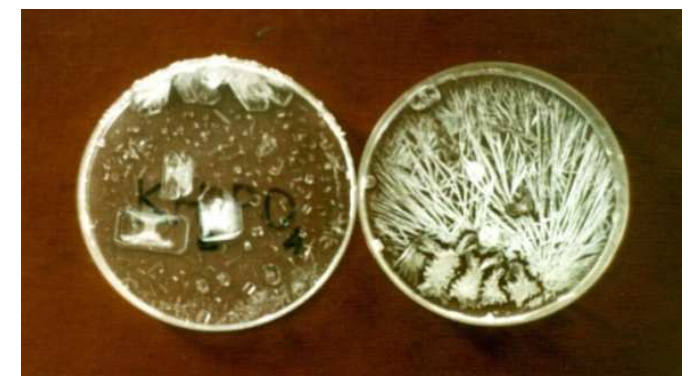

Fig. 3. $\mathrm{KH}_{2} \mathrm{PO}_{4}$ crystals. Left: the evaporation of solutions from the anode department of the electrolyzer formed crystals of the cubic form; right: the evaporation of solutions from the cathode department - the needle-shaped crystals.

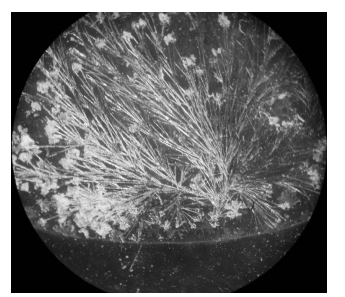

Fig. 4. Needle-shaped crystals formed during the evaporation of $\mathrm{NaCl}$ solutions from the cathode department electrolyzer.
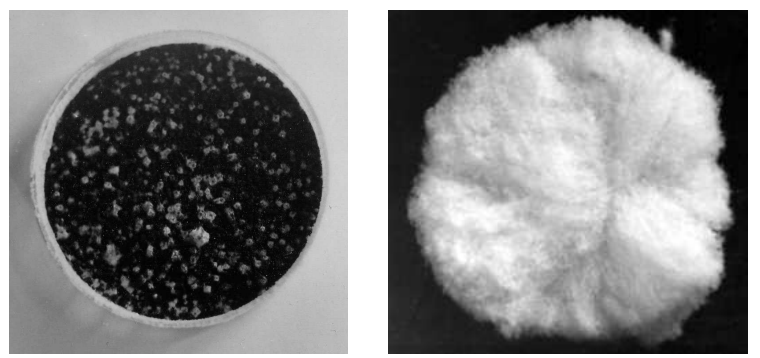

Fig. 5. Crystals of $\mathrm{NaCl}$. Left: on positively charged surface of activated carbon, pre-wetted with a solution of $\mathrm{NaCl}$, formed small cubic crystals; right: on negatively charged surface of silica gel, pre-wetted with a solution of $\mathrm{NaCl}$, formed needle-shaped crystals. 
Furthermore, since water obtains the negative charge (potential) during evaporation, in [5-8], can to conclude that state and UV absorbance of aqueous DNA should be depend on the conditions, in which the DNA working solutions are stored or water used for their preparation. Thus, an $A_{260}$ of DNA solution depends not only on content of oxygen, in [911]. In this connection, it should be recognized: $A_{260}$ cannot be used to accurately determine the concentration of DNA. Therefore, the exact DNA concentration should be determined by the concentration of products color reactions for phosphates, in [12].

This conclusion also says the following results.

\subsection{UV Absorption of Electrified Empty Photometric Cuvette}

The inner walls of empty photometric cuvettes were electrified (by a quartz rod, grated wool). It was found that UV absorption spectra of electrified cuvettes have broad peaks in the range $190-220 \mathrm{~nm}$ (fig 6).

Thus, the true cause of the UV absorption in the range 190 $-220 \mathrm{~nm}$ may be due to the UV absorption cuvette electrified. This is possible because quartz is piezoelectric, in [2]. Thus, the test UV absorption may have piezoelectric or piezo chemical nature

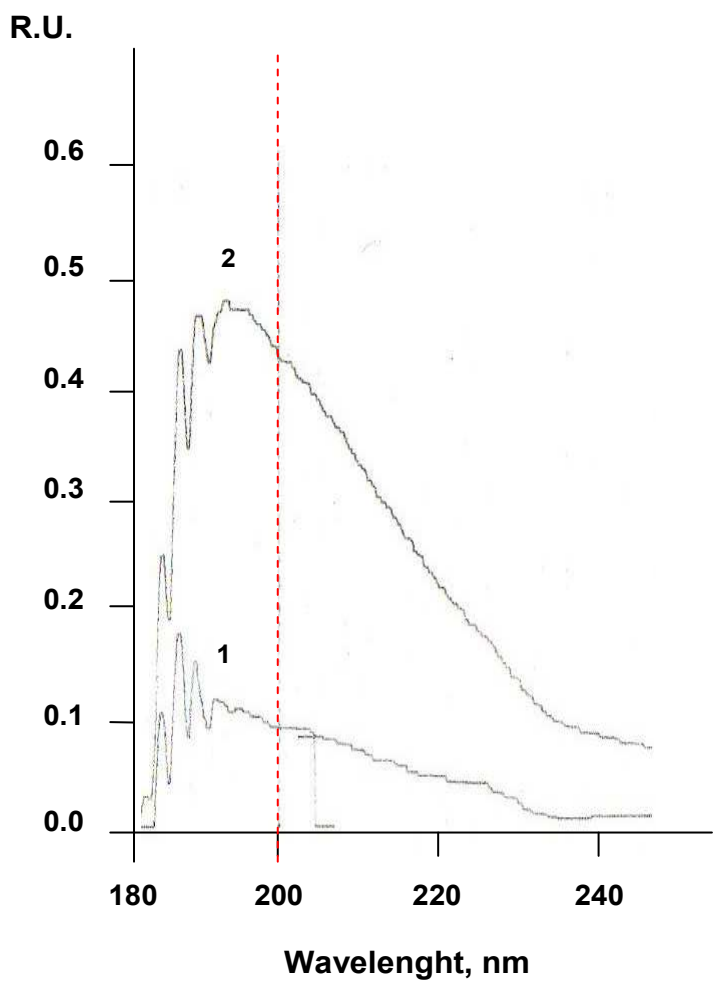

Fig. 6. UV absorbance spectra of the cuvette: 1 - before electrifying; 2 after electrifying. The spectra were not processed.

\subsection{UV Absorbance of the Water Solutions of Surface-Active and Surface-Inactive Materials}

UV absorption spectra water solutions of surface-inactive and surface-active materials were obtained. It was found that UV absorption spectra of aqueous sodium and potassium chlorides, sulfates, acetates, phosphates and hydroxides, ammoniac, glycerin, inorganic acids (hydrochloric, sulfuric, phosphoric), i.e. - of surface-inactive materials, in [2,3] have the sharp peaks in the range $190-200 \mathrm{~nm}$. On the other hand, UV absorption spectra of aqueous methanol, ethanol, acetone, sodium and potassium palmitate, lauryl sulfate, stearate, i.e. of surface-active materials, in [2,3], have the broad peaks in the range $200-220 \mathrm{~nm}$.

Thus, it can be concluded that UV absorbance of water solutions in the range $190-220 \mathrm{~nm}$ does not reflect the composition of dissolved materials. At the same time, the UV absorbance of water solutions can to definitely depend on the surface activity of solutes.

Since surface activity has an electric nature, we supposed that solutions of surface-inactive materials act on the cuvette as similar as negatively charged water and solutions of surface-active materials - as positively charged water.

\section{Conclusions}

UV absorbance of aqueous DNA does not explain by the $\mathrm{n} \rightarrow \pi$ - and $\pi \rightarrow \pi$-transitions of electrons nucleic bases.

UV absorbance of DNA water solutions depends on their electric charge (potential) or (and) on the surface activity solutes, compounds of buffers.

The true cause of the UV absorption of DNA water solutions in the range $190-220 \mathrm{~nm}$ can be UV absorption of electrified quartz photometric cuvette.

\section{References}

[1] Shabarova Z.A. and Bogdanov A.A. (1978) Chemistry of Nucleic Acids and their Components, Moscow: Chemistry.

[2] Nekrasov B.V. (1974) Bases of General Chemistry 1, Moscow: Chemistry.

[3] Fridrichsberg D.A. (1974) Course of Colloid Chemistry Leningrad: Chemistry.

[4] Stark, K.B.; Gallas, J.M.; Zajac G.W.; Golab, J.T.; Gidanian, S.; McIntire, T.; Farmer, P.J. (2005) The effect of stacking and redox state on optical absorption spectra of melanins- a comparison of theoretical and experimental results. J. Phys. Chem. B., 109, 1970-1977.

[5] Israel H., and Knopp R. (1962) Zum Problem der Ladungbildung beim Verdaumpfen, Arch. Meteorol., Geophys. and Bioklimatol. A13, 199-206.

[6] Latham J., and Stow C.D. (1965) Electrification of evaporation of ice crystals. Materials of Intern. Conf. in Tokyo, 352-356.

[7] Krasnogorskaja N.V. (1984) Electromagnetic fields in the earth's atmosphere and their biological significance 1, Moscow: Nauka.

[8] Pivovarenko, Y. (2015) A Charge Distribution in the Earth's Atmosphere American Journal of Physics and Applications. 3 (3), 67-68. 
[9] Doshi, R., Day, P. J. R., and Tirelli, N. (2009) Dissolved oxygen alteration of the spectrophotometric analysis and quantification of nucleic acid solutions. Biochemical Society Transactions, 37(2), 466-470.

[10] Doshi, R., Day, P.J.R., Carampin, P., Blanch, E., Statford, I.J. and Tirelli, N. (2010) Spectrophotometric analysis of nucleic acids: oxygenation-dependant hyperchromism of DNA. Anal. Bioanal. Chem., 396, 2331-2339.
[11] Pivovarenko, Y. V. (2014) Hypochromism degassed solutions of DNA Modern high technologies. 3, 147-150.

[12] Mergny, J.-L., Li, J., Lacroix, L., Amrane, S. and Chaires, J. B. (2005) Thermal difference spectra: a specific signature for ucleic acid structures. Nucleic Acids Res., 33(16), 1-6. 